\section{Spatial Relationships of Soil Physical Attributes with Yield and Lateral Shoot Growth of Garlic}

\author{
Job Teixeira de Oliveira \\ Universidade Federal do Maranhão, Chapadinha, 65500-000, Brazil
}

Rubens Alves de Oliveira and Domingos Sarvio Magalhães Valente

Universidade Federal de Viçosa, Viçosa, 36570-000, Brazil

Isabela da Silva Ribeiro
Universidade Federal do Maranhão, Chapadinha, 65500-000, Brazil

Paulo Eduardo Teodoro

Universidade Federal de Mato Grosso do Sul, Chapadão do Sul, 79560-000, Brazil

Additional index words. Allium sativum, geostatistics, irrigation, precision agriculture, pseudogrowth

\begin{abstract}
Some compaction states cause changes in soil structure, resulting in increased soil density and soil resistance to penetration (RP). The objective of this study was: a) to analyze the variability of the studied attributes of the plant and the soil; b) define the linear and spatial correlations between plant and soil attributes; and c) to identify the best attributes that correlate spatially with garlic yield (GY) and lateral shoot growth (LSG) for the elaboration of spatial variability maps. The attributes evaluated were GY, apparent soil electrical conductivity (EC), mechanical resistance to penetration (MRP), soil volumetric moisture (SVM), plant water potential (WP), and LSG. The reach values of spatial dependence to be considered in future studies using the same attributes should be between $8 \mathrm{~m}$ for apparent soil EC and $23 \mathrm{~m}$ for RP. From a spatial point of view, garlic LSG could be estimated by indirect cokriging with soil RP. Values greater than $3000 \mathrm{kPa}$ of soil RP indicated the sites with the lowest GYs.
\end{abstract}

The presence of physiological abnormalities in garlic (Allium sativum L.) is one of the factors that cause the most reduction in crop yield. Garlic LSG is an anomaly of genetic and physiological causes characterized by the early sprouting of bulbils (cloves) before harvest. It is a characteristic that negatively influences the garlic culture, because, in addition to reducing commercial bulb yield, it depreciates the product, causing its market value to be compromised (Puiatti, 2017).

The roots homogeneously exploit the soil under ideal conditions for root development, and the soil volume is relatively greater than in soils with compaction problems (Valadão et al., 2015). Some compaction states cause changes in soil structure, resulting in increased soil density and soil RP (Cortez et al., 2018).

Received for publication 14 Apr. 2020. Accepted for publication 29 Apr. 2020.

Published online 26 May 2020

This study was financed in part by the Coordenação de Aperfeiçoamento de Pessoal de Nível Superior, Brazil (CAPES), finance code 001. This work was carried out with support from $\mathrm{CNPq}$, Conselho Nacional de Desenvolvimento Científico e Tecnológico Brazil (141231/2019-0).

J.T.O. is the corresponding author. E-mail: job. oliveira@hotmail.com.

This is an open access article distributed under the CC BY-NC-ND license (https://creativecommons. org/licenses/by-nc-nd/4.0/).
In an attempt to develop techniques of indirect measurement of soil attributes, apparent soil EC has been highlighted. One of its usefulness in agriculture stems from the fact that soil mass, with its variability in physicochemical composition, presents different levels of apparent soil EC (Machado et al., 2015).

In view of these facts, this research aimed: a) to analyze the variability of the studied attributes of the plant and the soil; b) define the linear and spatial correlations between plant and soil attributes; and c) to identify the best attributes that correlate spatially with GY and LSG for the elaboration of spatial variability maps.

\section{Materials and Methods}

The study was carried out in the Irrigation and Drainage Area of the Federal University of Viçosa, in Viçosa, Minas Gerais, Brazil, at the followings geographic coordinates: $23 \mathrm{~K}$, $722569.09 \mathrm{~m} \mathrm{E} ; 7701897.59 \mathrm{~m} \mathrm{~S}$ (UTM), with an average elevation of $651 \mathrm{~m}$ with climate Cwa.

The soil in which the experimental grids were installed was classified according to the Brazilian System of Soil Classification as a Latossolo Vermelho Amarelo, with a sandy clay texture. The results of the granulometric analysis (in the 0.0-0.2-m layer) were 460, 150, and $390 \mathrm{~g} \cdot \mathrm{kg}^{-1}$ sand, silt, and clay, respectively.
In the field, with a conventional planting system in the irrigated area, plowing, harrowing, and operation with rototiller were carried out to prepare the seedbeds for the planting of garlic. The area was prepared between 1 and 5 May 2018, and on 7 May 2018 the purple garlic cultivar Ito was sown. Each sampling point was $1.60 \mathrm{~m}$ wide and $1.60 \mathrm{~m}$ long, with an area of $2.56 \mathrm{~m}^{2}$, with three double garlic rows. The useful area was the central row; the adjacent areas were used as borders. The ends $(0.30 \mathrm{~m})$ of the center rows were also disregarded for evaluation purposes, being used as a border. The spacing between the double rows was $0.40 \mathrm{~m}$, and was $0.10 \mathrm{~m}$ between the rows of the double rows.

The $x$ and $y$ directions of the Cartesian coordinate system were defined, and the experimental grid was demarcated near the end of the garlic cycle - that is, in mid Sept. 2018 - with a space of $1.60 \mathrm{~m}$ between them. Each experimental grid was composed of three transects of $48.00 \times 1.60 \mathrm{~m}$.

Drip irrigation was applied, and monitoring of the water requirement of the crop was carried out using the Irrigameter (Irrigâmetro, Viçosa, Brazil). GY was obtained by weighing the mass of the bulb, expressed in kilograms per hectare. LSG was obtained by the percentage of plants with LSG at each sampling point.

Apparent soil EC was obtained with the aid of the Electrical Resistivity LandMapper, model ERM-02. The device was used to measure the electrical resistivity (in millisiemens per meter) in a surface layer of 0 to $0.40 \mathrm{~m}$ using a four-electrode probe $1 \mathrm{~d}$ after harvest (14 Sept. 2018).

MRP and RP1, RP2, RP3, and RP4 - where the number that follows the attribute refers to the depth ( 1 is $0-0.10 \mathrm{~m}, 2$ is $0.10-0.20 \mathrm{~m}, 3$ is $0.20-0.30 \mathrm{~m}$, and 4 is $0.30-0.40 \mathrm{~m}$ ); and MRP refers to the resistance to penetration in the $0-0.40-\mathrm{m}$ layer - were calculated by the mean of all readings made at each $0.005-\mathrm{m}$ depth. For the determination of soil RP, a Falker PenetroLog-PLG 1020 digital penetrometer (Falker, Porto Alegre, Brazil) was used.

SVM, measured in kilograms per kilogram on 14 Sept 2018, was determined using a Falker HidroFarm with a measuring sensor (HFM1010) length of $0.20 \mathrm{~m}$, and with humidity results expressed as a percentage.

WP of the garlic plant was obtained using the Scholander pressure bomb (model SEC3005H07G4P40). A garlic leaf was cut and inserted into the chamber with a salient tip relative to the species support. Pressure was applied inside the chamber until the pressure exceeded the inner tension of the plant tissue, and the xylem sap began to flow from the cut region of the sample. The potential was then read directly from the manometer, expressed in kilopascals, at $86 \mathrm{~d}$ after planting, obtaining the WP before irrigation (WPB) and at $87 \mathrm{~d}$ after planting and $6 \mathrm{~h}$ after irrigation depth application (WPA).

For each attribute studied, a classic descriptive analysis was performed using the Rbio statistical program. To express the functional relationship graphically among the correlation estimates between the traces, a 

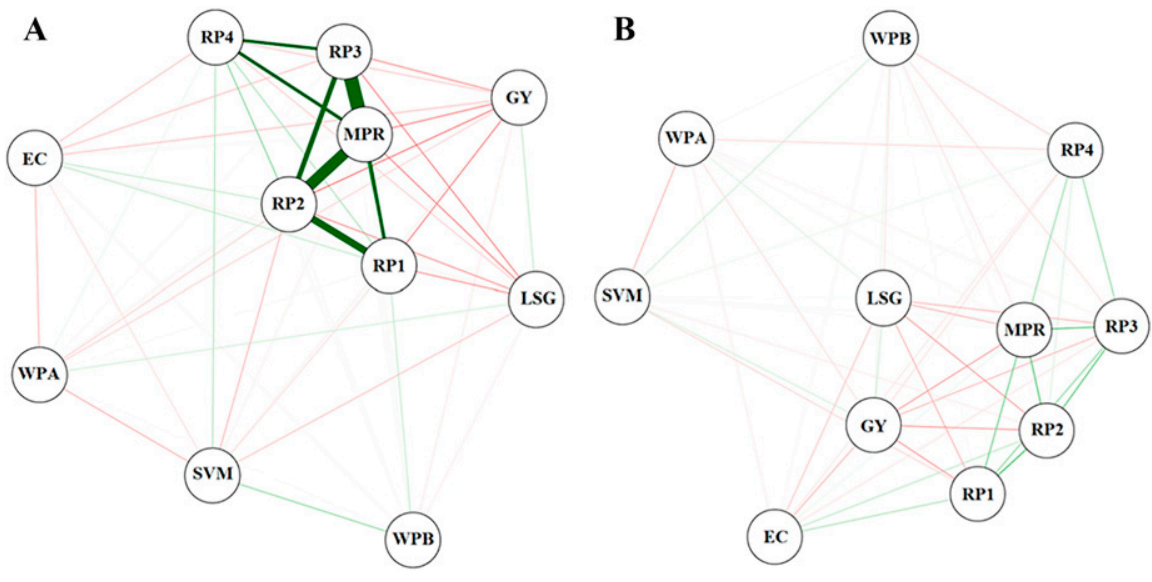

Fig. 1. Pearson (A) and Moran (B) correlations networks of attributes studied: garlic yield (GY), apparent soil electrical conductivity (EC), resistance to penetration (RP1, RP2, RP3, RP4), mechanical resistance to penetration (MRP), soil volumetric moisture (SVM), plant water potential (WPB, WPA) and lateral shoot growth (LSG).

correlation network was used in which the proximity between nodes (traces) was proportional to the absolute value between their correlations. The thickness of the edges was controlled by applying a cutoff value of 0.50 . The positive correlations were represented in green and the negative correlations were represented in red.

The spatial correlation analysis was performed using GeoDA free and open-source software. Moran's global and local bivariate indexes were calculated among the attributes studied. For each attribute, their spatial dependence was analyzed by the simple semivariogram calculation. To obtain the ideal number of neighbors, the kriging and cokriging maps were obtained through interpolation to analyze the dependence and the spatial interdependence between the attributes.

\section{Results and Discussion}

Through the Pearson correlation network (Fig. 1A), a negative correlation was found between GY and EC, RP1, RP2, RP3, RP4, and MRP $(-0.154<r<-0.348)$. For LSG, there was a significant negative correlation with RP1, RP2, RP3, RP4, RPM, and SVM, ranging from $-0.105^{*}<r<-0.302$. These results confirm the close negative correlation between GY and LSG with the RP studied.

A significant positive correlation between GY and LSG was found $(r=0.126)$. It is worth noting the significant positive correlations between RP (RP1, RP2, RP3, RP4, and MRP) between RP3 and MRP. Dalchiavon et al. (2014), studying penetration resistance in an Argissolo Vermelho Eutrófico, also found a positive and significant correlation between RP1 and RP2. Lima et al. (2017) found a significant correlation between RP1 and RP2 in a típico Quartzarênico soil.
The Moran correlation network (Fig. 1B) showed a negative correlation between GY and EC, RP1, RP2, RP3, RP4, and MRP. For LSG, there was a negative correlation with EC, RP1, RP2, RP3, RP4, MRP, and WPB. These results confirm the close negative correlation between GY and LSG of garlic with the RP studied. The Pearson and bivariate local Moran's I correlation analyses indicated a great similarity between the results, differing in the level of correlation between the attributes, but respecting the sense of direct and indirect correlations.

In the summary of the statistical analysis descriptive the soil RP in the different layers studied (Supplemental Table 1), an increase of RP with depth up to the 0.30 - to $0.40-\mathrm{m}$ layer was observed, where the maximum values of soil compaction were found. The geostatistical analysis (Supplemental Table 2) showed that there was spatial dependence for the simple semivariograms of the attributes RP2, RP4, and SVM that conformed to the spherical model, whereas GY, EC, RP1, RP3, MRP, and WPB adjusted to the exponential model. The values of the cross-semivariograms, $G Y=f(E C)$ and $G Y=f(R P 3)$, were adjusted to the spherical model, whereas all others were adjusted to the Gaussian model.

The attributes of the simple semivariograms obtained reaches ranging from $2.5 \mathrm{~m}$ (SVM) to $35.0 \mathrm{~m}$ (LSG). Thus, these soil and plant attributes showed that their distribution in space is not random, because their spatial dependence classes ranged from $44.5 \%$ (moderate to RP1) to $99.9 \%$ (strong for EC). However, analyzed by the reach magnitude $\left(\mathrm{A}_{\mathrm{o}}\right)$ of the crossed semivariograms, ranged from 21.0 to 40.4 for $G Y=f(R P 2)$, $\mathrm{GY}=\mathrm{f}(\mathrm{EC})$, respectively. The knowledge of the reach values and the coordinates of the areas, where the major checks and the small- est ones of a certain physical variable are concentrated, are essential for the management planning imposed in the preparation of the soil, in precision agriculture.

There were significant linear correlations between GY and LSG with the other attributes, with satisfactory semivariographic adjustments. Therefore, analyzing Supplemental Table 2, it can be inferred, for example, that RP was a good indicator of GY and LSG in sandy clay soil.

When we analyzed the cokriging maps (Supplemental Fig. 1) between GY according to EC, RP1, RP2, RP3, MRP, and WPB, we observed that the northern regions of the maps were the locations where there were medium to high yields, and the points distributed in the central and southern regions showed the lowest yields. Our analysis of the cokriging maps (Supplemental Fig. 2) for LSG according to soil RP clearly show greater percentages of LSG in the north of the map, whereas the southern part showed a smaller percentage of the anomaly studied.

\section{Conclusions}

1. The lower the soil RP, the greater the GY.

2. The characteristics: GY, apparent soil EC, soil MRP, SVM, plant WP, and LSG presented spatial dependence.

3. From the spatial point of view, garlic LSG could be estimated by indirect cokriging with soil RP.

\section{Literature Cited}

Cortez, J.W., W.P.D.S. Matos, S.N. Arcoverde, V.H. Cavassini, and I.Q. Valente. 2018. Spatial variability of soil resistance to penetration in no tillage system. Eng. Agr. 38(5):697-704.

Dalchiavon, F.C., M.P. Carvalho, R. Montanari, M. Andreotti, and E.A.D. Bem. 2014. Interrelações da produtividade de cana soca com a resistência à penetração, umidade e matéria orgânica do solo. Revista Ceres, Viçosa 61(2):255-264.

Lima, E.S., R. Montanari, L.H. Lovera, M.C.M.T. Filho, V.E. da Silva, and C.G.R. Lima. 2017. Spatial variability of eucalyptus and physical attributes of soil fertilized with lime mud and mineral fertilizer. Braz. J. Agr. Rev. Agr. 92(2):132-146.

Machado, F.C., R. Montanari, L.S. Shiratsuchi, L.H. Lovera, and E.D.S. Lima. 2015. Spatial dependence of apparent soil electrical conductivity and chemical properties of the soil by electromagnetic induction. Rev. Bras. Ciênc. Solo 39(4):1112-1120.

Puiatti, M. 2017. Exigências climáticas e ecofisiologia do alho. In: C. Nick and A. Borém (eds.). Alho: Do plantio à colheita. Viçosa, MG: Editora UFV .

Valadão, F.C.A., O.L. Weber, D.D.V. Júnior, A. Scarpinelli, F.R. Deina, and A. Bianchini. 2015. Adubação fosfatada e compactação do solo: Sistema radicular da soja e do milho e atributos físicos do solo. Rev. Bras. Ciênc. Solo 39(1):243-255. 


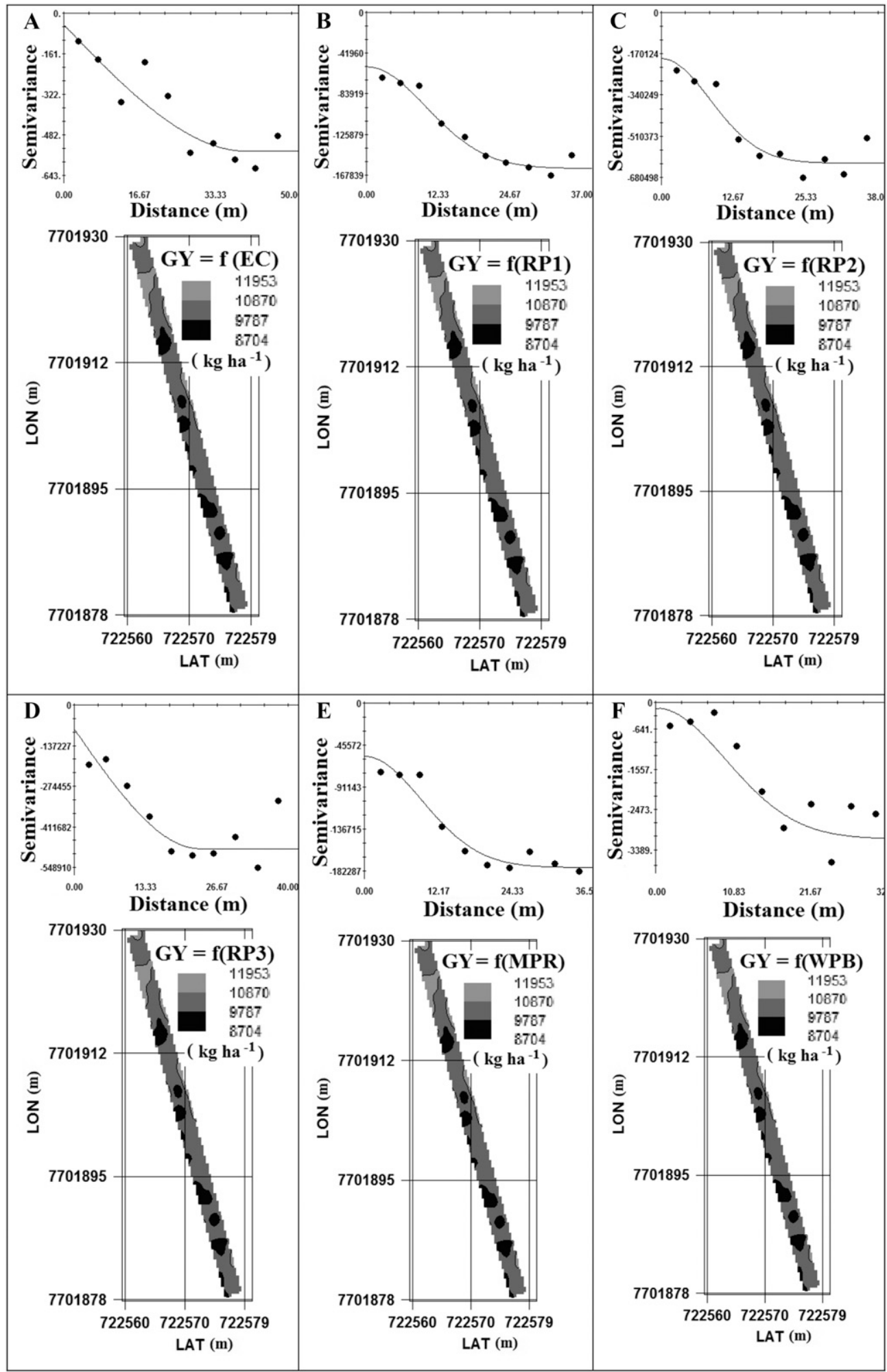

Supplemental Fig. 1. Crossed semivariograms and cokrigagem maps of the garlic yield according to (A) electrical conductivity (EC), (B) resistance to penetration (RP) 1, (C) RP2, (D) RP3, (E) mechanical resistance to penetration (MRP), and (F) plant water potential (WPB). 


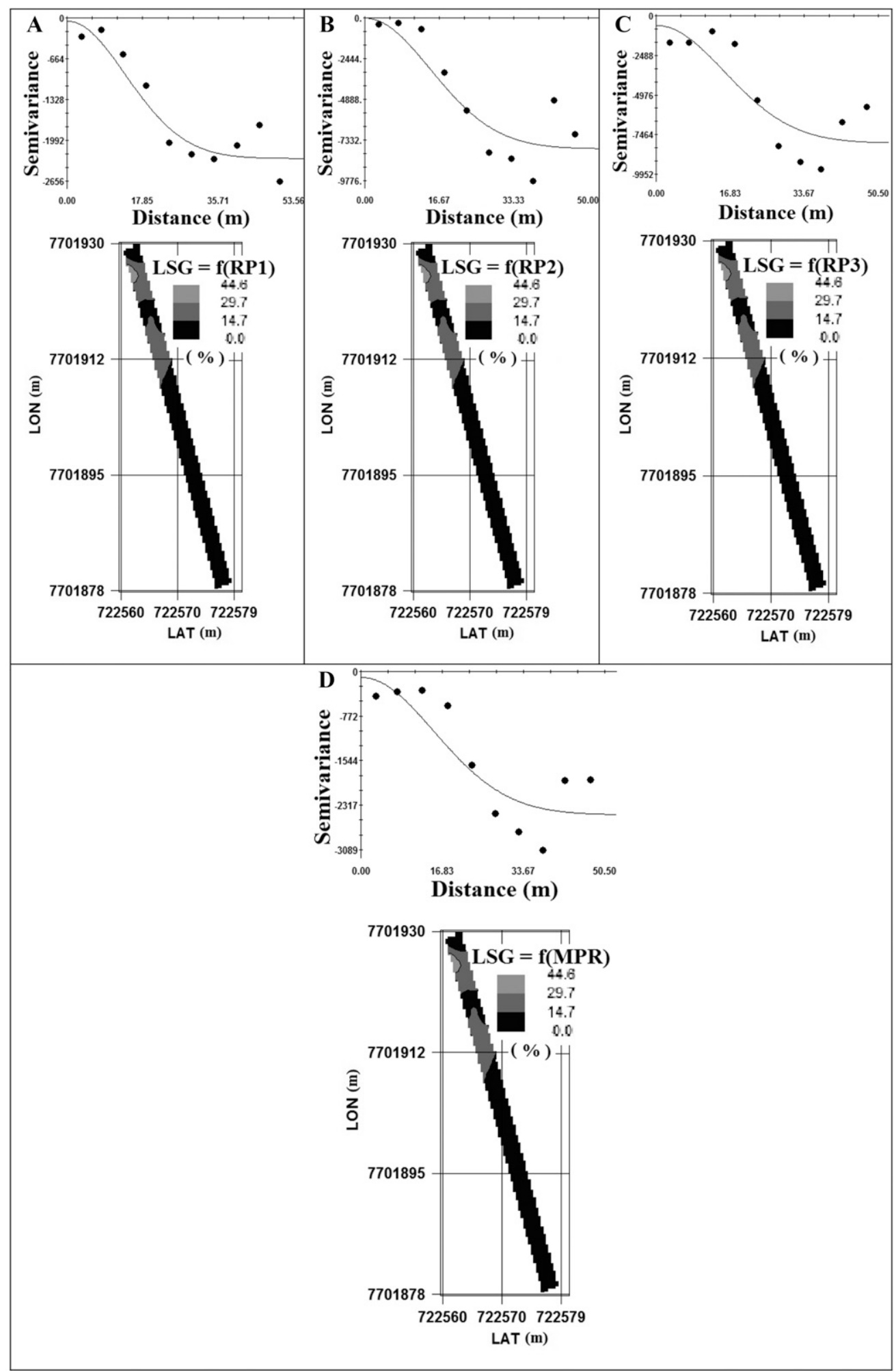

Supplemental Fig. 2. Crossed semivariograms and cokrigagem maps of garlic lateral shoot growth according to (A) resistance to penetration (RP) 1, (B) RP2, (C) RP3, and (D) mechanical resistance to penetration (MRP). 
Supplemental Table 1. Descriptive statistics of the garlic yield (GY) components, apparent soil electrical conductivity (EC), and soil physical attributes.

\begin{tabular}{|c|c|c|c|c|c|c|c|c|c|c|}
\hline Attribute & Mean & Median & Minimum & Maximum & SD & Variation (\%) & Curthose & Asymmetry & $\operatorname{Pr}<\mathrm{W}$ & $\mathrm{FD}$ \\
\hline$\overline{\mathrm{GY}}$ & $10,351.0$ & $10,370.4$ & $8,370.4$ & $12,518.5$ & 840.4 & 8.1 & -0.11 & -0.10 & 0.6587 & $\mathrm{NO}$ \\
\hline RP1 & 668.7 & 551.5 & 137.0 & $2,240.0$ & 439.0 & 65.7 & 0.95 & 1.08 & $4 \times 10^{-6}$ & IN \\
\hline RP2 & $2,806.0$ & $2,602.5$ & 705.0 & $6,438.0$ & $1,478.0$ & 52.7 & -0.78 & 0.47 & 0.0010 & IN \\
\hline RP4 & $5,600.0$ & $5,684.0$ & $2,752.0$ & $7,724.0$ & 969.0 & 17.3 & 0.07 & -0.45 & 0.2131 & $\mathrm{NO}$ \\
\hline MRP & $1,727.0$ & $1,811.0$ & 786.0 & $2,669.0$ & 432.0 & 25.0 & -0.62 & -0.17 & 0.1434 & $\mathrm{NO}$ \\
\hline SVM & 25.3 & 25.0 & 17.4 & 35.2 & 4.0 & 15.8 & -0.57 & 0.30 & 0.3189 & $\mathrm{NO}$ \\
\hline LSG & 9.3 & 6.3 & 0.0 & 46.9 & 9.4 & 100.3 & 3.10 & 1.55 & $3 \times 10^{-8}$ & IN \\
\hline
\end{tabular}

GY in kilograms per hectare; $\mathrm{EC}=$ apparent soil $\mathrm{EC}$ in millisiemens per meter; RP $x=$ resistance to penetration measured in kilopascals; $\mathrm{MRP}=$ mechanical resistance to penetration measured in kilopascals; $\mathrm{SVM}=$ soil volumetric moisture measured in kilograms per kilogram; WPB, WPA = plant water potential measured in kilopascals; $\mathrm{LSG}=$ lateral shoot growth measured as a percentage; $\mathrm{FD}=$ frequency distribution; $\mathrm{NO}=$ normal type; $\mathrm{IN}=$ indeterminate.

Supplemental Table 2. Estimated parameters for the simple and crossed semivariogram of the garlic yield (GY) components, apparent soil electrical conductivity (EC), and soil physical attributes.

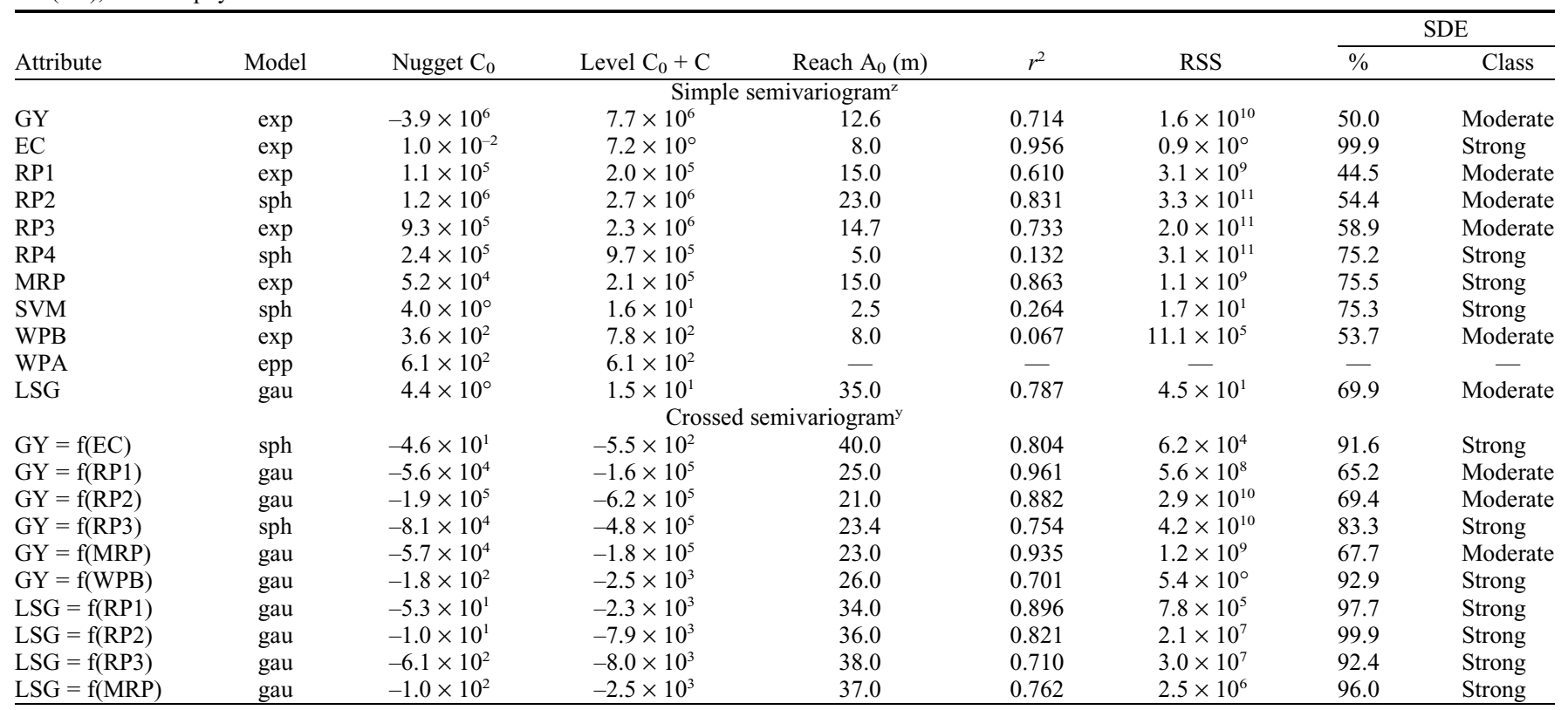

${ }^{\mathrm{z}}$ Simple semivariograms: GY in kilograms per hectare; $\mathrm{EC}=$ apparent soil $\mathrm{EC}$ in millisiemens per meter; $\mathrm{RP} x=$ resistance to penetration measured in kilopascals; $\mathrm{MRP}=$ mechanical resistance to penetration measured in kilopascals; $\mathrm{SVM}=$ soil volumetric moisture measured in kilograms per kilogram; $\mathrm{WPB}, \mathrm{WPA}=$ plant water potential measured in kilopascals; LSG = lateral shoot growth measured as a percentage.

${ }^{\mathrm{y}}$ Crossed semivariograms: $\mathrm{GY}$ according to $\mathrm{f}(\mathrm{CE})=$ apparent soil $\mathrm{EC}, \mathrm{f}(\mathrm{RP} 1)=$ resistance to penetration from 0 to $0.10 \mathrm{~m}, \mathrm{f}(\mathrm{RP} 2)=$ resistance to penetration from 0.10 to $0.20 \mathrm{~m}, \mathrm{f}(\mathrm{RP} 3)=$ resistance to penetration from 0.20 to $0.30 \mathrm{~m}, \mathrm{f}(\mathrm{RPM})=$ mean resistance to penetration from 0 to $0.40 \mathrm{~m}, \mathrm{f}(\mathrm{WPB})=$ plant water potential before irrigation. $\mathrm{LSG}$ according to $\mathrm{f}(\mathrm{RP} 1)=$ resistance to penetration from 0 to $0.10 \mathrm{~m}, \mathrm{f}(\mathrm{RP} 2)=$ resistance to penetration from 0.10 to $0.20 \mathrm{~m}, \mathrm{f}(\mathrm{RP} 3)=$ resistance to penetration from 0.20 to $0.30 \mathrm{~m}, \mathrm{f}(\mathrm{MRP})=$ mean resistance to penetration from 0 to $0.40 \mathrm{~m}$.

$\mathrm{sph}=$ spherical; gau $=$ Gaussian; $\mathrm{epp}=$ pure nugget; RSS $=$ residual sum of squares; $\mathrm{SDE}=$ spatial dependence estimator. 